\title{
Enkele goederenrechtelijke aspecten van octrooirechten
}

\author{
Bespreking van het proefschrift van mr. M.W.D. van der Burg
}

$$
\text { Mr. M.E.A. Möhring* }
$$

\section{Inleiding}

Het octrooirecht biedt, kort gezegd, bescherming aan technische uitvindingen. Zolang het octrooi geldig is, heeft de octrooihouder het uitsluitend recht om de uitvinding te gebruiken. Hiermee wordt de uitvinder voor zijn uitvinding beloond, wat - zo is de gedachte - ook het doen van uitvindingen stimuleert. Bij dat laatste is de maatschappij als geheel gebaat. $^{1}$

De nationaalrechtelijke regeling voor het octrooi is in Nederland te vinden in de Rijksoctrooiwet 1995 (ROW 1995). ${ }^{2}$ Uit die wettelijke regeling blijkt dat een octrooi niet van rechtswege wordt verkregen: om een octrooi te krijgen moet een aanvraag worden ingediend en moet op die aanvraag positief worden beslist. Voor Nederlandse octrooien dient de octrooiaanvraag te worden ingediend bij het Octrooicentrum Nederland (hierna: het Octrooicentrum), dat vervolgens beslist of het octrooi wordt verleend. ${ }^{3}$ Over de vraag aan welke vereisten moet worden voldaan voordat een octrooi wordt verleend, zijn boeken volgeschreven. In het kort komt het erop neer dat voor het verlenen van een octrooi vereist is dat de uitvinding (1) nieuw is, (2) inventief is en (3) vatbaar is voor toepassing op het gebied van de nijverheid. ${ }^{4}$

Zowel de aanvraag voor een octrooi als de status van die aanvraag wordt gepubliceerd in het octrooiregister. De publicatie is van groot belang. De rechthebbende op het octrooi is namelijk degene van wie de aanvraag als eerste in het octrooiregister staat opgenomen, zelfs al heeft een ander de uitvinding eerder gedaan. Door de publicatie in het octrooiregister komen uitvindingen bovendien in de openbaarheid. Dat leidt in de eerste plaats ertoe dat anderen van de uitvinding kennis kunnen

Mr. M.E.A. Möhring is advocaat in de cassatiesectie van Pels Rijcken te Den Haag.

1 J.L.R.A. Huydecoper, P.A.C.E. van der Kooij, C.J.J.C. van Nispen \& T. Cohen Jehoram, Industriële eigendom. Deel 1, Wolters Kluwer: Deventer 2016, par. 3.1.6.

2 Op Europees niveau is met name het Europees Octrooiverdrag van belang. Dat speelt in het proefschrift van Van der Burg echter geen rol en wordt hier dan ook verder buiten beschouwing gelaten.

3 Huydecoper e.a. 2016, par. 3.1.2. Zie ook art. 15 ROW 1995.

4 Art. 2 ROW 1995 nemen en vervolgens op de uitvinding kunnen voortbouwen, wat een maatschappelijk doel dient. Maar de publicatie heeft ook een belangrijke functie ten opzichte van derden. Door de publicatie kunnen derden namelijk worden geacht van het octrooi op de hoogte te zijn. ${ }^{5}$

Daarmee kom ik op het onderwerp van het proefschrift van Van der Burg, dat betrekking heeft op de goederenrechtelijke aspecten van het octrooi. Daarbij is het proefschrift als volgt opgezet. $\mathrm{Na}$ een algemene inleiding in hoofdstuk 1 volgen twee verkennende hoofdstukken. Het eerste verkennende hoofdstuk - hoofdstuk 2 - gaat over het octrooi. Daarbij komt onder andere aan de orde wat een octrooi is, hoe een octrooi wordt verkregen, hoe een octrooi wordt verloren en hoe het octrooi moet worden ingebed in het vermogensrecht. Het tweede verkennende hoofdstuk - hoofdstuk 3 - ziet op het octrooiregister en het register van stukken. De inhoud en werking van deze registers komen in dit hoofdstuk aan de orde, waarbij ook een parallel wordt getrokken met het kadaster en de openbare registers.

Met deze verkennende hoofdstukken wordt toegewerkt naar de kern van het proefschrift: de overdracht van het octrooi (art. 65 ROW 1995). In hoofdstuk 4 wordt de huidige wettelijke regeling rondom de overdracht van het octrooi, zoals neergelegd in art. 65 ROW 1995, uitgebreid besproken. In hoofdstuk 5 worden vervolgens enkele voorstellen gedaan tot modernisering van art. 65 ROW 1995. In de resterende hoofdstukken worden enkele aanpalende goederenrechtelijke kwesties rondom het octrooi besproken. Achtereenvolgens komen daarbij aan de orde het bezit van een octrooi (hoofdstuk 6), het pandrecht op een octrooi (hoofdstuk 7) en de licentie (hoofdstuk 8).

Het proefschrift kent hiermee een logische opbouw. Wel lijken hoofdstuk 6 tot en met 8 enigszins los te staan van hoofdstuk 1 tot en met 5. Dat houdt waarschijnlijk ermee verband dat hoofdstuk 1 tot en met 5 betrekking hebben op wat Van der Burg aanwijst als de aanleiding van zijn onderzoek - art. 65 lid 3 ROW 1995 en de rol van het octrooiregister. De drie

$5 \quad$ Huydecoper e.a. 2016, par. 3.1.2 en 3.1.6. 


\section{Maandblad \\ Vermogensrecht}

daaropvolgende hoofdstukken gaan over andere goederenrechtelijke onderwerpen. Al deze hoofdstukken passen binnen het - ruime - thema van het proefschrift: goederenrechtelijke kwesties rondom het octrooi. In het proefschrift komen dan ook veel verschillende goederenrechtelijke kwesties aan de orde. Dat roept de vraag op of een nadere afbakening - bijvoorbeeld ten aanzien van de overdracht van het octrooi - het proefschrift niet toegankelijker zou hebben gemaakt. Tegelijkertijd zou dan weer een gebrek aan volledigheid kunnen worden tegengeworpen.

In het navolgende zal ik enkele van de goederenrechtelijke kwesties uit het proefschrift van Van der Burg uitlichten. Achtereenvolgens kom ik daarbij te spreken over de overdracht van het octrooi (par. 2), het pandrecht op het octrooi (par. 3) en de licentie (par. 4).

\section{De overdracht van het octrooi (art. 65 ROW 1995)}

De overdracht van een octrooi is geregeld in art. 65 ROW 1995. In art. 65 lid 1 ROW 1995 is, kort gezegd, opgenomen dat de levering - vereist voor de overdracht van het octrooi geschiedt bij akte. Zoals Van der Burg signaleert, is hiermee sprake van een 'stille overdracht'. Dat kan problematisch zijn voor derden, die daardoor immers in beginsel niet van de overdracht op de hoogte zijn. Over de positie van derden is dan ook een nadere regeling getroffen in art. 65 lid 3 ROW 1995. In die bepaling is opgenomen dat de overdracht tegenover derden eerst werkt nadat de akte is ingeschreven in het octrooiregister. Die bepaling roept bij Van der Burg verschillende vragen op. Want, zoals hij schrijft, wat is nu een overdracht die niet tegenover derden werkt? Kan dat eigenlijk wel? En - in het verlengde daarvan - is art. 65 lid 3 ROW 1995, ondanks de tekst van die bepaling, niet juist een derdenbeschermingsbepaling in plaats van een derdenwerkingsbepaling?

Om tot een beantwoording van deze vragen te komen, gaat Van der Burg in hoofdstuk 2 eerst in op de positie van het octrooi in het vermogensrecht. Dat is een hoofdstuk dat duidelijk tot doel heeft het kader te schetsen tegen de achtergrond waarvan de hiervoor genoemde vragen kunnen worden beantwoord. Van der Burg concludeert onder meer (1) dat octrooien vermogensrechten in de zin van art. 3:6 BW zijn, en (2) dat het octrooi een absoluut recht is.

Ook hoofdstuk 3 is verkennend van aard. In dat hoofdstuk gaat Van der Burg in op de werking van het octrooiregister en het register van stukken. Het is daarmee een vrij technisch-juridisch hoofdstuk. Van der Burg constateert dat er in feite twee registers zijn. Het eerste is het octrooiregister zelf. In het octrooiregister staat bijvoorbeeld vermeld wie octrooihouder is en wie in het verleden octrooihouder was. Daarnaast is er ook een tweede register: het register van stukken. In dat register zijn de achterliggende stukken opgenomen, zoals bijvoorbeeld de akte waarmee het octrooi is overgedragen. In de praktijk worden het octrooiregister en het register van stukken samen gezien als 'het octrooiregister'. Toch bestaan er verschillen tussen beide registers. Van der Burg wijst erop dat met betrekking tot het octrooiregister (overwegend) een zogeheten negatief stelsel van grondboekhouding wordt gehanteerd. Dat betekent dat het Octrooicentrum niet controleert of de feiten in de hem aangeboden stukken juist zijn. Ook betekent dit dat de inschrijving in het octrooiregister dus geen rechten schept. Dat roept de vraag op wat dit betekent voor derden, die afgaan op de juistheid van het octrooiregister.

In dat verband maakt Van der Burg een interessante vergelijking met de openbare registers voor onroerende zaken. Feiten die voor de rechtstoestand van registergoederen van belang zijn, moeten op grond van de wet worden ingeschreven in de openbare registers. Hierbij kan bijvoorbeeld worden gedacht aan de overdracht van een onroerende zaak, waarbij in de openbare registers moet worden ingeschreven dat de onroerende zaak is overgedragen. Dat gebeurt doordat de onderliggende akte wordt ingeschreven. De openbare registers vormen daarbij een samenspel met het kadaster. In het kadaster is de kadastrale aanduiding van een onroerende zaak te vinden, maar ook is daarin vermeld (1) wie de huidige eigenaar is, (2) welke beperkte rechten gevestigd zijn op de onroerende zaak en (3) de vindplaatsen van akten en andere stukken in de openbare registers. Het kadaster wordt dus bijgewerkt naar aanleiding van de inschrijving van de feiten die voor de rechtstoestand van registergoederen van belang zijn, in de openbare registers. Op het moment dat de akte met betrekking tot de overdracht van een onroerende zaak in de openbare registers wordt ingeschreven, wordt aan de hand daarvan het kadaster bijgewerkt. Derden kunnen vervolgens via het kadaster de akten in de openbare registers terugvinden.

Van der Burg constateert dat het register van stukken dat bij het octrooiregister hoort, vergeleken kan worden met die openbare registers. Beide registers zijn immers een genummerde verzameling van (onder andere) akten van levering en hypotheek- en pandakten. Het octrooiregister zelf is te vergelijken met de kadastrale registratie. Zowel het octrooiregister als de kadastrale registratie geeft de goederenrechtelijke stand van zaken volgens het bestuursorgaan aan.

Derden kunnen hun eventuele bescherming alleen ontlenen aan de openbare registers - maar (in beginsel) niet aan de kadastrale registratie. ${ }^{6}$ In gelijke zin zouden derden, waar het gaat om octrooien, hun eventuele bescherming alleen kunnen ontlenen aan het register van stukken, maar (in beginsel) niet aan het octrooiregister. Bijkomend probleem bij het register van stukken is nog dat dit - anders dan de openbare registers - onvolledig is. Het is namelijk - anders dan bij de openbare registers - niet vereist om akten in het register van stukken in te schrijven, zo schrijft Van der Burg. Dat laatste zou in mijn visie een (mogelijke) verklaring kunnen zijn voor art. 65 lid 3 ROW

6 Vgl. ook concl. A-G Valk van 19 juni 2020, ECLI:NL:PHR:2020:609, onder 3.6. 


\section{Maandblad Vermogensrecht}

1995. Die bepaling strekt dan ertoe om duidelijk te maken dat als de akte niet in het register van stukken is ingeschreven, dat (in beginsel) niet voor risico van derden komt. Ofwel: als de akte in het register van stukken is ingeschreven, is uitgangspunt dat de akte aan derden kan worden tegengeworpen. Is de akte niet in het register van stukken ingeschreven, dan is uitgangspunt dat de akte niet aan derden kan worden tegengeworpen.

Tegen de achtergrond van het in hoofdstuk 2 en 3 geschetste kader bespreekt Van der Burg in hoofdstuk 4 (de parlementaire geschiedenis van) art. 65 ROW 1995. Uit zijn onderzoek blijkt dat art. 65 ROW 1995 is gebaseerd op de tekst van het Ontwerp tot herziening van het Burgerlijk Wetboek uit 1899 en nadien nauwelijks is gewijzigd. Dat is problematisch, omdat deze ontwerpwet nooit wet is geworden en goederenrechtelijk gezien andere uitgangspunten kende dan het huidige BW.

Van der Burg constateert dat bij de invoering van het huidige BW door de wetgever is verduidelijkt dat het octrooi géén registergoed is. Dat maakt duidelijk dat de inschrijving van de akte van levering in het octrooiregister geen constitutief vereiste is voor de overdracht van het octrooi. Daarmee blijft echter de vraag wat de betekenis is van het derde lid van art. 65 ROW 1995, en in het bijzonder de zinsnede dat de overdracht pas tegen derden werkt na inschrijving in het octrooiregister.

Uit de parlementaire geschiedenis van rond 1900 blijkt dat ook de oorsprong van deze zinsnede dateert uit 1899 . In de eerste voorstellen voor wat nu art. 65 ROW 1995 is, was - in lijn met het Ontwerp tot herziening van het Burgerlijk Wetboek - bepaald dat de overdracht van een octrooi pas werkte na inschrijving. De bedoeling was dus om inschrijving in het octrooiregister een constitutief vereiste voor de overdracht te laten zijn. Op enig moment in het wetgevingsproces is in de bepaling echter de zinsnede 'tegenover derden' ingevoegd in de passage over de werking van de overdracht. Van der Burg schrijft niet te hebben kunnen achterhalen waarom en wanneer dat is gebeurd. Wel wordt in de (latere) parlementaire geschiedenis opgemerkt dat de inschrijving van de overdracht nodig is, omdat van belang is dat eenieder weet wie rechthebbende op het octrooi is. Benadrukt wordt daarbij dat inschrijving tot doel heeft derden voor te lichten en niet is bedoeld om hindernissen op te werpen met betrekking tot de werking van de akte.

Dat het inschrijven van de akte geen vereiste is voor overdracht, maar is bedoeld om derden te beschermen, blijkt ook uit een arrest van de Hoge Raad in $1950 .^{7}$ De Hoge Raad heeft in dat arrest ook verduidelijkt dat een derde die weet van de overdracht, zich niet erop kan beroepen dat de akte van overdracht niet is ingeschreven in het octrooiregister. Deze jurisprudentie - net zoals de parlementaire geschiedenis - lijkt dus

7 HR 15 december 1950, ECLI:NL:HR:1950:17, NJ 1951/469. erop te wijzen dat art. 65 lid 3 ROW 1995 een derdenbeschermingsbepaling is en geen derdenwerkingsbepaling.

In hoofdstuk 5 constateert Van der Burg echter dat art. 65 lid 3 ROW 1995 problematisch blijft. Het kan geen derdenwerkingsbepaling zijn, omdat (1) het octrooi geen registergoed is en (2) een overdracht die niet tegenover derden werkt, zich niet goed laat voorstellen. Tegelijkertijd kan het geen derdenbeschermingsbepaling zijn, omdat art. 65 lid 3 ROW 1995 niet de woorden 'goede trouw' bevat en dat wel hoort bij een derdenbeschermingsbepaling, zo legt Van der Burg uit. Volgens hem moet er dan ook worden gekozen uit twee opties. De eerste is dat de inschrijving van de akte van overdracht in het octrooiregister een constitutief vereiste voor overdracht wordt. Dat is een eenvoudig stelsel, maar daarmee zou Nederland wel uit de pas lopen ten opzichte van onder andere Duitsland, Engeland en Frankrijk. De tweede optie is dat van art. 65 lid 3 ROW 1995 een uitdrukkelijke derdenbeschermingsbepaling wordt gemaakt. Dat zou niet alleen stroken met het stelsel van de genoemde landen, maar ook met het systeem van het BW.

Van der Burg pleit - mijns inziens terecht - voor de tweede optie. Die optie strookt immers met de betekenis die sinds het arrest van de Hoge Raad uit 1950 aan het huidige art. 65 lid 3 ROW 1995 wordt gegeven, en die ook door de wetgever is bevestigd bij de inwerkingtreding van het nieuw BW. In feite moet het huidige art. 65 lid 3 ROW 1995 dus aldus worden uitgelegd dat de zin 'de overdracht werkt tegenover derden eerst wanneer de akte in het octrooiregister is ingeschreven' moet worden gelezen als 'de overdracht kan tegenover derden die te goeder trouw zijn eerst worden ingeroepen wanneer de akte in het octrooiregister is ingeschreven'. Dat de tekst van art. 65 lid 3 ROW 1995 niet helemaal accuraat lijkt te zijn, lijkt in de praktijk ook niet tot problemen te leiden. Het is mijns inziens dan ook de vraag of een wetswijziging op dit punt nodig is.

\section{Pandrecht (art. 67 ROW 1995)}

In hoofdstuk 7 gaat Van der Burg in op het pandrecht op een octrooi. De wettelijke regeling voor het vestigen van een pandrecht op een octrooi is te vinden in art. 67 ROW 1995. In art. 67 lid 1 ROW 1995 is opgenomen dat het pandrecht op een octrooi wordt gevestigd bij akte en tegenover derden eerst werkt wanneer de akte door het Octrooibureau in het octrooiregister is ingeschreven. Daarmee bevat art. 67 lid 1 ROW 1995 een met art. 65 lid 3 ROW 1995 vergelijkbare bepaling. Het ligt om die reden voor de hand dat Van der Burg ook dit onderwerp bij zijn onderzoek heeft betrokken. Door de gelijkenis tussen beide bepalingen lijkt een gelijke uitleg van beide bepalingen aangewezen, zodat voor een goed begrip van art. 65 lid 3 ROW 1995 ook art. 67 lid 1 ROW 1995 van belang is.

Van der Burg gaat in zijn onderzoek echter verder dan alleen art. 67 lid 1 ROW 1995. Zo gaat hij onder meer ook in op het tweede lid van art. 67 ROW 1995. In die bepaling is geregeld dat (1) de pandhouder verplicht is woonplaats te kiezen te 


\section{Maandblad \\ Vermogensrecht}

Den Haag, en (2) als de pandhouder dat niet doet, als gekozen woonplaats het Octrooibureau heeft te gelden. Van der Burg schrijft het nut of de werking van deze bepaling niet te hebben kunnen achterhalen en stelt om die reden voor deze bepaling te schrappen of aan te passen.

Een mogelijke verklaring voor deze bepaling zou mijns inziens nog kunnen zijn dat hiermee wordt bewerkstelligd dat ook vorderingen die over het pandrecht op het octrooi worden ingesteld tegen de pandhouder, op grond van de gekozen woonplaats van de pandhouder terecht zouden komen bij de rechtbank en het hof Den Haag. De rechtspraak over octrooien wordt immers in belangrijke mate gecentreerd bij deze instanties, nu de rechtbank Den Haag op grond van art. 80 ROW 1995 exclusief bevoegd is ten aanzien van de meeste octrooirechtelijke geschillen. Tegen de gedachte dat dit de reden is voor de verplichte woonplaatskeuze in art. 67 lid 2 ROW 1995 pleit echter dat het in dat geval eenvoudiger zou zijn geweest om ook ten aanzien van geschillen over het pandrecht op het octrooi in art. 80 ROW 1995 te regelen dat de genoemde instanties exclusief bevoegd zijn van een dergelijk geschil kennis te nemen.

\section{Licentie}

In hoofdstuk 8 bespreekt Van der Burg de licentie op een octrooi. Een licentie geeft de licentiehouder blijkens art. 56 ROW 1995 het recht om handelingen te verrichten die zonder licentie in strijd zouden zijn met het uitsluitend recht van de octrooihouder. Met andere woorden: de licentiehouder mag - op de in de licentie overeengekomen wijze - de uitvinding waarop het octrooi ziet gebruiken. De licentie op een octrooi komt in de praktijk veel voor, omdat het een gemakkelijke manier is om de uitvinding breed in te zetten. Dit heeft vanzelfsprekend ook een maatschappelijk belang. Van der Burg analyseert - in lijn met de reikwijdte van zijn onderzoek - de goederenrechtelijke aspecten van de octrooilicentie. Daarbij gaat hij onder andere in op de vraag hoe de licentie op een octrooi moet worden gekwalificeerd. Is het een beperkt recht, of juist een vorderingsrecht?

De licentie op een octrooi komt tot stand op basis van een overeenkomst. In zoverre is de licentie verbintenisrechtelijk van aard. Tegelijkertijd kan de licentie de licentiehouder het recht geven om (zelfstandig) inbreukmakers aan te spreken. Daarbij kan de licentiehouder echter alleen schadevergoeding vorderen, geen inbreukverbod. Verder kan de licentie worden ingeschreven in het octrooiregister. Het gevolg van inschrijving in het octrooiregister is dat de licentie derdenwerking krijgt, onder meer ten opzichte van latere verkrijgers van het octrooi.

Dat alles betekent echter niet dat 'dus' sprake is van een beperkt recht, zo constateert Van der Burg terecht. De licentie wordt immers niet - zoals bij beperkte rechten het geval is gevestigd op grond van art. 3:98 en 3:84 lid 1 BW. In plaats daarvan is voor wat betreft de werking van de licentie ten op- zichte van latere verkrijgers van het octrooi, zo merkt hij op, eerder een parallel te trekken met de positie van huurders bij de overdracht van het pand dat zij huren aan een andere verkrijger ('koop breekt geen huur'). Die omstandigheid maakt ook bij huur niet dat om die reden sprake is van een beperkt recht. In dat verband kan worden gewezen op een conclusie van A-G Wuisman, die een onderscheid maakt tussen het beperkte recht van gebruik en bewoning en het verbintenisrechtelijke huurrecht:

'Het recht van gebruik en bewoning is een species van het recht van vruchtgebruik (...) en daarmee een beperkt recht, dat ontstaat (...) door de goederenrechtelijke handeling van vestiging (...) en gelding heeft tegenover derden. (...) Het huurrecht ontstaat krachtens overeenkomst en is in beginsel alleen geldend te maken tegenover de contractuele wederpartij, zij het dat "koop" geen huur breekt (...).'

In de visie van Van der Burg dient het huidige stelsel met betrekking tot de licentie - een verbintenisrechtelijke totstandkoming, gevolgd door goederenrechtelijke derdenwerking bij inschrijving in het octrooiregister - te worden gemoderniseerd. De wens tot modernisering lijkt Van der Burg vooral te zijn ingegeven om aan te kunnen sluiten bij de (nog in werking te treden) Overeenkomst betreffende een eengemaakt octrooigerecht (hierna: de UPC-Overeenkomst). ${ }^{\text {? }}$

De weg naar de inwerkingtreding van de UPC-Overeenkomst is er een van een lange adem gebleken. De UPC-Overeenkomst is al in 2013 ondertekend, maar is ook nu - acht jaar later (en twee jaar na het sluiten van het onderzoek door Van der Burg) - nog niet in werking getreden. De laatste hobbel - ratificatie door Duitsland - is inmiddels echter genomen, zodat de verwachting op dit moment is dat de inwerkingtreding eind 2022/begin $2023 \mathrm{zal}$ plaatsvinden. ${ }^{10}$ Het is om die reden onverminderd relevant om te kijken naar de UPC-Overeenkomst, zoals Van der Burg heeft gedaan. In de UPC-Overeenkomst wordt een onderscheid gemaakt tussen twee verschillende soorten licentiehouders (zie art. 47 UPC-Overeenkomst). De eerste is de exclusieve licentiehouder: die heeft dezelfde rechten om een procedure in te leiden als de octrooihouder, maar moet wel de octrooihouder op de hoogte stellen van het starten van de procedure. De tweede is de niet-exclusieve licentiehouder: die mag geen procedures inleiden, tenzij (1) hij de octrooihouder daarvan op de hoogte heeft gesteld en (2) in de licentieovereenkomst is opgenomen dat de licentiehouder procedures kan inleiden.

Concreet schetst Van der Burg twee mogelijke wegen om tot modernisering van de regeling over licenties op octrooien te komen.

8 Concl. A-G Wuisman van 29 mei 2009, ECLI:NL:PHR:2009:BI6321.

9 Trb. 2013, 92 en Trb. 2016, 1. UPC staat voor Unified Patent Court.

10 Zie www.rvo.nl/onderwerpen/innovatief-ondernemen/octrooien-ofwelpatenten/u-heeft-een-octrooi/inbreuk-en-nietigheid/europeesoctrooigerecht-upc. 


\section{Maandblad Vermogensrecht}

De eerste mogelijkheid die Van der Burg noemt, is om aan te sluiten bij het systeem uit de UPC-Overeenkomst. Dan zouden er dus twee soorten licentiehouders zijn. De eerste soort licentiehouder in deze benadering is de licentiehouder met een exclusief licentierecht. Als gekozen wordt voor deze moderniseringsmogelijkheid, zouden exclusieve licentierechten volgens Van der Burg moeten worden gekwalificeerd als een beperkt recht op een octrooi. Dit zou dus een wijziging van de wet vergen, omdat in het Nederlandse wettelijk stelsel de beperkte rechten limitatief in de wet zijn opgenomen. ${ }^{11}$ Het gevolg van het aanmerken van deze licenties als beperkt recht zou zijn dat deze licenties absoluut werken - en dus ook tegenover derden. In deze benadering moet van de licentiehouder met een exclusief licentierecht worden onderscheiden de licentiehouder met een relatief licentierecht. Relatieve licenties zouden niet moeten worden aangemerkt als een beperkt recht en dus ook niet jegens derden moeten kunnen worden gehandhaafd. Van der Burg benoemt als voordeel van deze mogelijke wijze van modernisering dat dit naadloos past in het Nederlandse goederenen vermogensrecht. Dat betekent dat het Nederlandse goederen- en vermogensrecht kan worden toegepast om vragen rondom (de werking van) licenties te beantwoorden.

De tweede mogelijke weg voor modernisering die Van der Burg noemt, is om alle octrooien te blijven aanmerken als verbintenissen - en dus niet als beperkt recht. Tegelijkertijd zou die verbintenisrechtelijke licentie in zijn visie dan wel enigszins moeten worden 'verzakelijkt' ('vergoederenrechtelijkt'). Dat zou, zo schrijft Van der Burg, met name erin gelegen zijn dat de licentienemer zelfstandig moet kunnen optreden tegen inbreukmakers, als dat tussen partijen zo zou zijn afgesproken, ook als de licentie niet in het octrooiregister is ingeschreven. Hiervoor zou een wettelijke regeling moeten worden getroffen. Daarnaast zou de licentie goederenrechtelijke derdenwerking moeten krijgen, ongeacht of de licentie in het octrooiregister is ingeschreven, aldus Van der Burg. Het voordeel van deze mogelijke wijze van modernisering is volgens hem dat hiermee flexibiliteit behouden blijft, terwijl tegelijkertijd de positie van de licentienemer bij overdracht van het octrooi stevig is verankerd. De vraag is mijns inziens echter wel of derden bij deze benadering nog voldoende zijn beschermd. Zij kunnen dan worden geconfronteerd met een optredende partij die stelt licentiehouder te zijn, zonder dat zij op voorhand wisten dat er een licentiehouder was en zonder dat zij op eenvoudige wijze kunnen verifiëren of diegene inderdaad licentiehouder is.

Van der Burg spreekt zelf een (lichte) voorkeur uit voor de tweede mogelijke weg voor modernisering. Er pleit echter ook het een en ander voor juist de eerste mogelijke weg voor modernisering, aansluiting bij de UPC-Overeenkomst.
Vanuit de gedachte dat de reden voor modernisering van de regeling over licenties op octrooien erin is gelegen aan te sluiten bij de UPC-Overeenkomst, ligt het immers voor de hand om dan ook daadwerkelijk aan te sluiten bij het systeem dat in de UPC-Overeenkomst wordt gehanteerd. Zou dat niet worden gedaan, zoals wanneer wordt gekozen voor de tweede mogelijke weg voor modernisering, dan blijft immers de situatie bestaan waarin de positie van een licentienemer onder de ROW 1995 afwijkt van de positie van de licentienemer onder de UPC-Overeenkomst. Bovendien is een groot voordeel van aansluiten bij de UPC-Overeenkomst - zoals Van der Burg zelf ook signaleert - dat daarmee het systeem past in het $\mathrm{Ne}$ derlandse goederen- en vermogensrecht. Dat is een groot goed, ook met het oog op eventueel in de toekomst op te komen en nu nog niet goed te voorziene - vermogensrechtelijke vragen met betrekking tot licenties op octrooien. Die vragen kunnen dan immers worden beantwoord aan de hand van het Nederlandse goederen- en vermogensrecht - net zoals bij andersoortige licenties.

Hierbij is de vraag echter wel of het voor de praktijk wenselijk is om een onderscheid te maken tussen (1) exclusieve licenties, die in deze benadering als beperkte rechten moeten worden aangemerkt en dus onder het goederenrecht vallen, en (2) relatieve licenties, die in deze benadering als vermogensrecht worden aangemerkt en dus onder het vermogensrecht vallen. Het aansluiten bij het systeem van de UPC-Overeenkomst lijkt een dergelijk onderscheid ook niet noodzakelijk voor te schrijven, omdat ook zou kunnen worden geregeld dat de exclusieve licentiehouder procesbevoegdheid heeft zonder dat de exclusieve licentie als beperkt recht wordt aangemerkt.

\section{Conclusie}

Het proefschrift van Van der Burg stelt op goede gronden aan de orde dat enkele goederenrechtelijke aspecten van het octrooirecht - die vaak al sinds het begin van de twintigste eeuw niet meer zijn gewijzigd - nadere aandacht behoeven. Tegelijkertijd gaat het om ingewikkelde materie, en lijkt de huidige regeling in de praktijk (vooralsnog) niet tot onoverkomelijke problemen te leiden. Dat de voorgestelde moderniseringsslag hoog op de prioriteitenlijst van de wetgever komt te staan, lijkt daarmee niet voor de hand te liggen. Dat neemt niet weg dat Van der Burg in zijn proefschrift een voorzet geeft voor nader debat en nadere rechtsontwikkeling op dit punt. Mogelijk dat ook de inwerkingtreding van de UPC-Overeenkomst hieraan een verdere impuls kan geven. Het zal dan ook interessant zijn verdere ontwikkelingen in de gaten te houden.

11 W.H.M. Reehuis \& A.H.T. Heisterkamp, Pitlo. Het Nederlands burgerlijk recht. Deel 3. Goederenrecht, Deventer: Wolters Kluwer 2019/591. 